\title{
Effects of Reliability Index on Optimal Configuration of Hybrid Solar/Battery Energy System by Optimization Approach: A Case Study
}

\author{
Hao Liu, ${ }^{1}$ Baojia Wu $\mathbb{D}^{1}$ Akbar Maleki $\mathbb{D}^{2},{ }^{2}$ Fathollah Pourfayaz $\mathbb{D},^{3}$ \\ and Roghayeh Ghasempour ${ }^{3}$ \\ ${ }^{1}$ Department of Physics, College of Science, Yanbian University, Yanji, Jilin 133000, China \\ ${ }^{2}$ Faculty of Mechanical Engineering, Shahrood University of Technology, Shahrood, Iran \\ ${ }^{3}$ Department of Renewable Energies, Faculty of New Science \& Technologies, University of Tehran, Tehran, Iran \\ Correspondence should be addressed to Baojia Wu; jbwuybdx@163.com and Akbar Maleki; akbar.maleki20@yahoo.com
}

Received 17 July 2021; Revised 1 September 2021; Accepted 6 October 2021; Published 28 October 2021

Academic Editor: Siamak Hoseinzadeh

Copyright ( 2021 Hao Liu et al. This is an open access article distributed under the Creative Commons Attribution License, which permits unrestricted use, distribution, and reproduction in any medium, provided the original work is properly cited.

\begin{abstract}
Stand-alone hybrid energy systems based on solar and energy storage are an effective option for rural areas to meet the load demand. The objective of the current work is to the optimal configuration of a stand-alone hybrid photovoltaic/battery energy storage system with the help of an efficient metaheuristic algorithm, improved harmony search, to supply electrical of a residential load in Iran. The objective function is a minimization of total life cycle cost (TLCC) subject to the reliability index (loss of load probability). The optimal configurations of hybrid systems are compared in respect of different losses of load probability (0 to 20\%). Sensitivity analysis and effects of economic parameters based on photovoltaic and battery prices are carried out to study the possibility of the suggested scheme. The results show that, by increasing the reliability index from 0 to $20 \%$, the optimal number of panels and batteries decreases by 52 and 1202. Also, it is found that the TLCC of the system and cost of system components are increased by decreasing of the reliability index value.
\end{abstract}

\section{Introduction}

The provision of electricity is one of the key elements for the economic growth of a country. Around $17 \%$ of people in the countries, specifically those living in isolated regions, still have no contact with electricity $[1,2]$. Due to the high cost of network transmission to remote areas, mainly, diesel generators are used to supply load demands to remote locations. Due to the high cost of fuel, environmental pollutants, and the shortage of fossil fuels, diesel power generation is not always a beneficial and cost-effective solution. To solve this problem, the use of renewable energy has been considered by many researchers in recent years. Renewable energy systems, especially solar PV systems, are an effective solution for stand-alone locations [3].

However, uncertainty in solar radiation and the dependence of solar systems on the climate is a problem for pro- viding continuous load in remote areas. So it is a viable solution for stand-alone locations to consider a PV system with an energy storage unit initially. Among storage systems, the battery is one of the most popular [4-7]. In this regard, it is necessary to define the optimal configuration of power scheme components to remote areas to supply the load demand with the minimum cost and maximum reliability. Therefore, efficient modeling and a powerful optimization method to solve these problems are essential.

Several studies in the literature have focused on investigating mathematical modeling, optimal sizing, and technoeconomic analysis of hybrid energy schemes based on solar energy. Javed et al. [2] used a genetic algorithm to optimize a hybrid solar/wind system with storage for an isolated island. The results were compared with that of the HOMER (hybrid optimization of multiple energy resources) software. Das et al. [8] obtained a techno-economic optimal design of 
a stand-alone hybrid solar/biogas/energy storage scheme for a radio transmitter station in India by metaheuristic optimization techniques. Saedpanah et al. [9] used a multiobjective optimization model for designing an off-grid photovoltaic system in remote areas of Iran. Asrami et al. [10] used three scenarios based on a genetic algorithm to find the optimal solution to utilize PV systems for residential buildings in urban areas. Nagapurkar and Smith [11] developed a methodology for optimizing small-scale microgrids based on solar/wind/battery/biodiesel/hydrogen systems located in the US cities of Tucson using a genetic algorithm. Yu et al. [12] presented an optimization method based on an adaptive marine predator algorithm to optimize a hybrid solar/diesel/storage system to meet the load demand of a remote location in Hoxtolgay, China. Ashraf et al. [13] proposed an optimization method for optimal configuration of a hybrid $\mathrm{PV} /$ diesel/battery energy system to a practical case study in Gobi Desert, China. Cho and Valenzuela [14] proposed an algorithm based on integer Nelder-Mead for designing the capacities of a residential stand-alone hybrid solar/battery system. Mukhopadhyay and Das [15] used particle swarm optimization for optimal sizing of stand-alone hybrid PV/battery systems in remote areas. Jiang et al. [16] proposed an optimization method to design the photovoltaic/battery energy storage systems with multiple types of batteries to minimize the total cost. Anoune et al. [17] presented a heuristic approach based on a genetic algorithm to the sizing-optimization of a photovoltaic-wind-battery based on hybrid system to minimize the total cost. Ajiwiguna et al. [18] developed an algorithm for optimizing the capacities of the stand-alone battery-less PV-reverse osmosis system and their capacity combination to find the lowest water cost.

Various theories and methods have been studied on power systems [19-25]; in this regard, several optimization methods have been presented on the investigation of optimal sizing of hybrid solar energy systems, including HOMER software [26-30], genetic algorithm [31], tabu search [32], simulated annealing [33], particle swarm optimization [34], grey wolf optimizer [35], harmony search [36-38], and global dynamic harmony search [39]. Yu et al. [40] proposed an efficient framework based on harmony search to find the suitable capacity and location for off-grid PV/battery systems. It is found that the optimization algorithm based on harmony search offers better results than the simulated annealing algorithm.

Previously mentioned researches have mainly focused on optimization hybrid energy systems based on solar energy with the lowest total cost. Some studies have also examined the impact of the reliability index (RI) on the hybrid energy system. Previously, studies usually used the HOMER software tool to perform techno-economic analyses based on the input information of hybrid systems. The HOMER software tools allow a quick hybrid energy system assessment, but changes in the modeling of hybrid system components are limited. The ability to modify mathematical models and input information for different renewable energy technologies is restricted in the HOMER tool. Also, in previous studies, a comprehensive analysis of the effects of critical economic parameters and reliability index on the optimization of hybrid systems by an efficient metaheuristic algorithm is rarely seen.

In this paper, an optimization model of a stand-alone PV/battery energy storage scheme to the optimal configuration of the hybrid system to supply electrical load demands is presented. The methodology followed in this study considered a remote area in Iran residential communities, namely, Rafsanjan. For optimal sizing of hybrid system components, an improved metaheuristic algorithm based on harmony search is presented. The objective function is a minimization of total life cycle cost (TLCC) and loss of load probability as a reliability index. To study the possibility of the suggested hybrid system, effects of economic parameters based on photovoltaic and battery prices are presented. Also, the optimal configurations of the hybrid system are compared in respect of different reliability indexes.

\section{System Modeling}

The stand-alone hybrid energy systems include a solar photovoltaic panel, storage unite based on battery, an inverter/converter system, and other devices and cables. In this system, first, the power generated by solar panels satisfies the required load. After satisfying the load demand, the power generated from PV panels is used to charge the battery bank to supply the load when sunlight is unavailable. Then, the extra battery charge level is dumped. To optimize the scheme, all of the system components must first be exclusively modeled and then their optimal sizing calculated to meet the load demand. The full model of the stand-alone hybrid solar/battery scheme is shown in Figure 1.

2.1. The Model of Photovoltaic (PV). The proposed model for generating power of PV panel $\left(p_{\mathrm{PV}}\right)$ based on the solar radiation $(\boldsymbol{R})$ and ambient temperature $\left(T_{\text {air }}\right)$ has been written as follows [41]:

$$
p_{\mathrm{PV}}(t)=P_{R, \mathrm{PV}} \times\left(\frac{R}{R_{\mathrm{ref}}}\right) \times\left[1+N_{T}\left(T_{c}-T_{\mathrm{ref}}\right)\right],
$$

where $P_{R, \mathrm{PV}}$ refers to the rated power of the utilized panel. $N_{T}, T_{\text {ref }}$, and $R_{\text {ref }}$ refer to the temperature coefficient (here $\left.-3.7 \times 10^{-3}\left(1 /{ }^{\circ} \mathrm{C}\right)\right)$, reference temperature (here $25^{\circ} \mathrm{C}$ ), and reference solar radiation (here $1000 \mathrm{~W} / \mathrm{m}^{2}$ ), respectively [42]. The temperature of the cell can be formulated as follows [41]:

$$
T_{c}=T_{\mathrm{air}}+\left(\left(\frac{(\mathrm{NOCT}-20)}{800}\right) \times R\right) .
$$

Here, NOCT refers to the normal operating cell temperature $\left({ }^{\circ} \mathrm{C}\right)$. The total produced power by $\mathrm{PV}$ panels is $P_{\mathrm{PV}}(t)=N_{\mathrm{PV}} \times p_{\mathrm{PV}}(t)$, based on number of panels $\left(N_{\mathrm{PV}}\right)$.

2.2. The Model of Battery Storage. To increase the reliability of the hybrid system and save the surplus output power of $\mathrm{PV}$, an energy storage unit (battery bank) has been used. When the output power of the PV system is higher than 


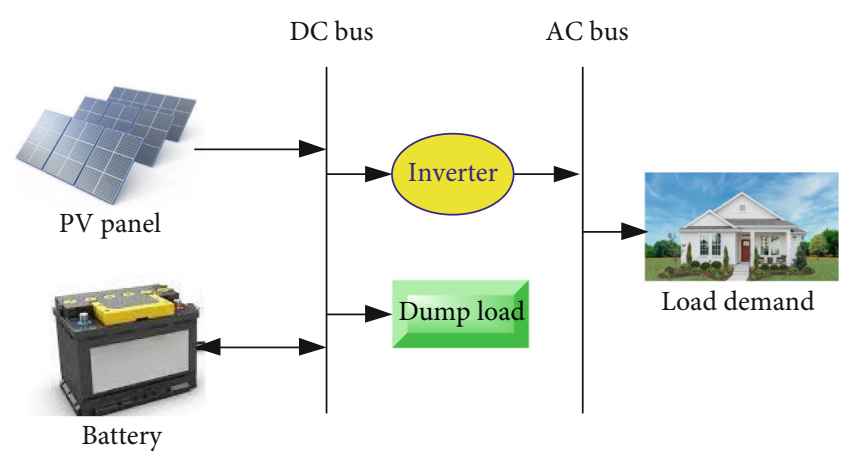

FIGURE 1: Stand-alone hybrid solar/battery system schematic.

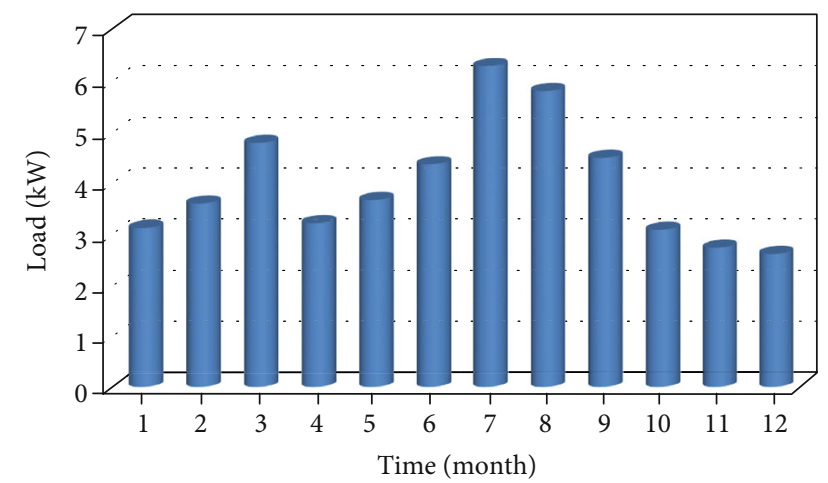

Figure 2: The residential load profile of the analyzed area.

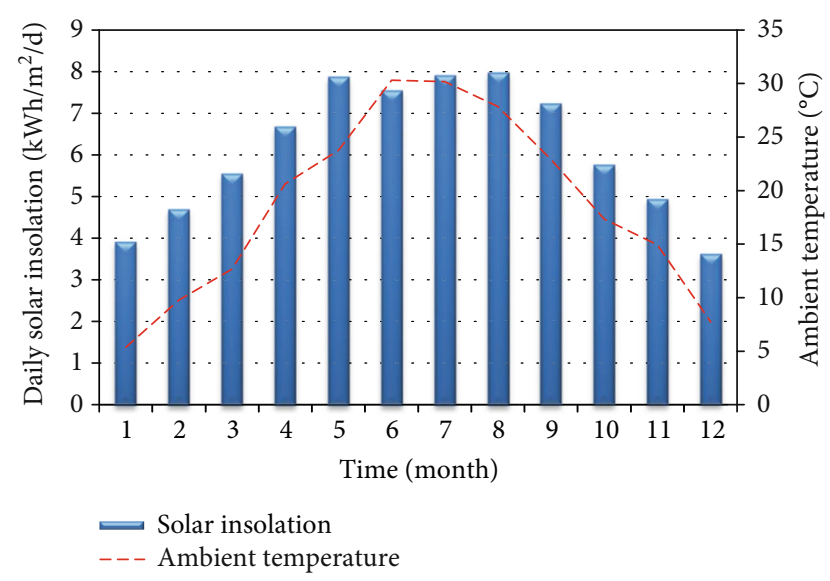

Figure 3: Solar insolation and ambient temperature of the analyzed area.

the required load, the energy storage unit will start charging. Energy storage is used, when the output power of the PV panels is insufficient to supply the load demand. At this time, the energy storage unit will start discharging. The state of charge of the battery storage unit during the time from $t$ $-\mathbf{1}$ to $\boldsymbol{t}$ is given in Equations (3) and (4) [43,44].

Charging state:

$$
S_{\mathrm{BAT}}(t)=S_{\mathrm{BAT}}(t-1) \cdot(1-\omega)+\left[\left(E_{\mathrm{PV}}(t)\right)-\frac{E_{L}(t)}{\eta_{\mathrm{INV}}}\right] \cdot \eta_{\mathrm{BC}}
$$

TABLE 1: Parameters of the hybrid system components.

\begin{tabular}{|c|c|}
\hline \multicolumn{2}{|c|}{ Economic [51] } \\
\hline$r$ & $10 \%$ \\
\hline$n$ & 20 years \\
\hline \multicolumn{2}{|c|}{ PV panel $[3,52]$} \\
\hline$P_{R, \mathrm{PV}}$ & $260 \mathrm{~W}$ \\
\hline $\mathrm{C} \& \mathrm{R}_{\mathrm{PV}}$ & $122 \$ / \mathrm{m}^{2}$ \\
\hline O\&MPV & $2 \% \mathrm{C}_{\mathrm{PV}} \$ / \mathrm{m}^{2} /$ year \\
\hline Efficiency & $15.8 \%$ \\
\hline \multicolumn{2}{|c|}{ Battery $[52,53]$} \\
\hline $\mathrm{NC}_{\mathrm{BAT}}$ & $2.1 \mathrm{kWh}$ \\
\hline$\eta_{\mathrm{BC}}$ & $85 \%$ \\
\hline$P_{\mathrm{BAT}}$ & $310 \$$ \\
\hline Life span & 5 years \\
\hline DOD & $80 \%$ \\
\hline$\omega$ & $0.02 \%$ \\
\hline O\&MBAT & $10 \$ /$ year \\
\hline \multicolumn{2}{|c|}{ Power converter/inverter [39] } \\
\hline Rated power & $3 \mathrm{~kW}$ \\
\hline$\eta_{\mathrm{INV}}$ & $95 \%$ \\
\hline Life span & 10 years \\
\hline$P_{\mathrm{INV}}$ & $1583 \$$ \\
\hline O\&MINV & 15 \$/year \\
\hline
\end{tabular}

Discharging state:

$$
S_{\mathrm{BAT}}(t)=S_{\mathrm{BAT}}(t-1) \cdot(1-\omega)-\left[\frac{E_{L}(t)}{\eta_{\mathrm{INV}}}-\left(E_{\mathrm{PV}}(t)\right)\right] / \eta_{\mathrm{BDC}} \cdot
$$

Here, $\omega, S_{\mathrm{BAT}}(t), \eta_{\mathrm{INV}}, \eta_{\mathrm{BC}}, \eta_{\mathrm{BDC}}$, and $E_{L}$ refer to the rate of hourly self-discharge, state of charge of the battery at time $\boldsymbol{t}$, the efficiency of the inverter, charging, and discharging of the battery (here 1), demand of load, respectively, and $t$ is the hourly time $(1 \mathrm{~h})$ [43-46].

2.3. The Model of Inverter. According to the output current of solar panels, a converter must be used to convert the direct current to alternating current. The output power of an inverter $\left(P_{\mathrm{INV}}\right)$ is obtained by the following Equation (12):

$$
P_{\mathrm{INV}}=\frac{P_{D}}{\eta_{\mathrm{INV}}},
$$

where $P_{D}$ is the hourly demand.

\section{The Objective Function and Constraints}

3.1. Objective Function. The objective function is a minimization of total life cycle cost (TLCC) subject to the loss of load probability (LLP). TLCC includes the annual operation and maintenance $(\mathrm{O} \& \mathrm{M})$ cost, which occur during the 


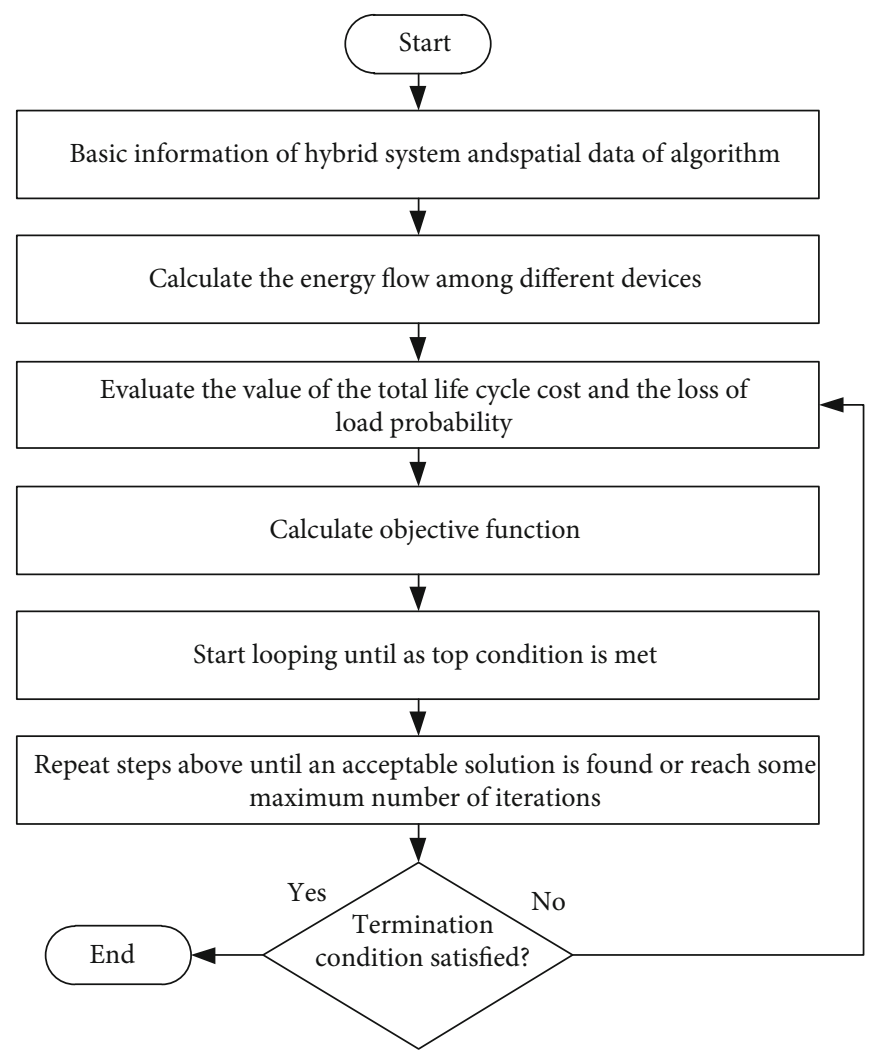

FIGURE 4: Flowchart of the suggested process.

TABLE 2: The optimal configuration of hybrid solar/battery energy system for different reliability indexes.

\begin{tabular}{lcccccccccc}
\hline RI (\%) & LLP (\%) & $N_{\mathrm{PV}}$ & $N_{\mathrm{BAT}}$ & $\mathrm{LCC}_{\mathrm{PV}}(\$)$ & $\mathrm{LCC}_{\mathrm{BAT}}(\$)$ & $\mathrm{C} \& \mathrm{R}(\$)$ & O\&M $(\$)$ & O\&M $_{\mathrm{PV}}(\$)$ & O\&M $_{\mathrm{BAT}}(\$)$ & TLCC $(\$)$ \\
\hline $0 \%$ & 0 & 184 & 1511 & 6530 & 13,8675 & 128,661 & 17,363 & 2,208 & 15,110 & 146,070 \\
$0.3 \%$ & 0.2968 & 181 & 1511 & 6424 & 13,8675 & 128,590 & 17,327 & 2,172 & 15,110 & 145,920 \\
$1 \%$ & 0.8227 & 179 & 1340 & 6353 & 12,2981 & 114,559 & 15,593 & 2,148 & 13,400 & 130,180 \\
$2 \%$ & 1.8516 & 172 & 1137 & 6105 & 10,4351 & 97,794 & 13,479 & 2,064 & 11,370 & 111,280 \\
$5 \%$ & 4.5051 & 160 & 858 & 5679 & 78,745 & 74,696 & 10,545 & 1,920 & 8,580 & 85,250 \\
$10 \%$ & 7.6983 & 153 & 698 & 5430 & 64,061 & 61,448 & 8,861 & 1,836 & 6,980 & 70,310 \\
$12 \%$ & 10.5065 & 147 & 590 & 5217 & 54,149 & 52,475 & 7,709 & 1,764 & 5,900 & 60,190 \\
$15 \%$ & 14.6732 & 140 & 430 & 4969 & 39,464 & 39,226 & 6,025 & 1,680 & 4,300 & 45,260 \\
$18 \%$ & 17.8040 & 135 & 341 & 4791 & 31,296 & 31,830 & 5,075 & 1,620 & 3,410 & 36,910 \\
$20 \%$ & 19.6356 & 132 & 309 & 4685 & 28,359 & 29,143 & 4,719 & 1,584 & 3,090 & 33,860 \\
\hline
\end{tabular}

project lifetime, and annual capital and replacement (C\&R) cost, which is as follows:

$$
\text { Minimize.TLCC }=\mathrm{C} \& \mathrm{R}+\mathrm{O} \& \mathrm{M}
$$

According to the capital cost and replacement cost, which occur in the beginning and during the project lifetime, the capital recover factor (CRF) based on the interest rate $(\boldsymbol{r})$ and system life span ( $\boldsymbol{n})$ is mathematically modeled as follows [47]:

$$
\mathrm{CRF}=\frac{r(1+r)^{n}}{(1+r)^{n}-1}
$$

Due to the lifetime of the batteries and inverters (here 5 and 10 years, respectively), their replacement should be considered in the optimization during the project lifetime. The present worth of battery $\left(C \& R_{B A T}\right)$ and inverter/converter $\left(\mathrm{C} \& \mathrm{R}_{\mathrm{INV}}\right)$ achieved as follows:

$$
\mathrm{C} \& \mathrm{R}_{\mathrm{BAT}}=P_{\mathrm{BAT}} \cdot\left(1+\frac{1}{(1+r)^{5}}+\frac{1}{(1+r)^{10}}+\frac{1}{(1+r)^{15}}\right),
$$

$\mathrm{C} \& \mathrm{R}_{\mathrm{INV}}=P_{\mathrm{INV}} \times\left(1+\frac{1}{(1+r)^{10}}\right)$ 


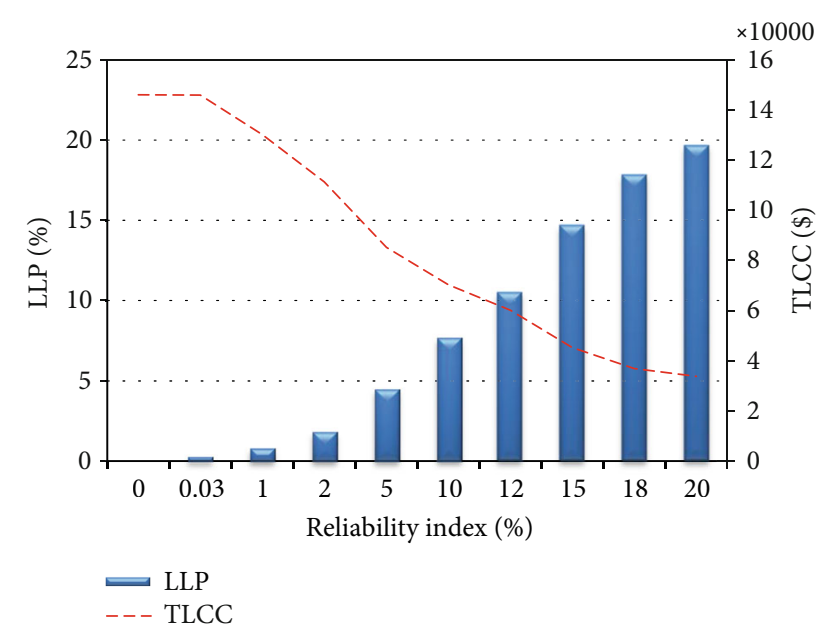

Figure 5: Total life cycle cost and loss of load probability vs. reliability indexes in the optimal condition.

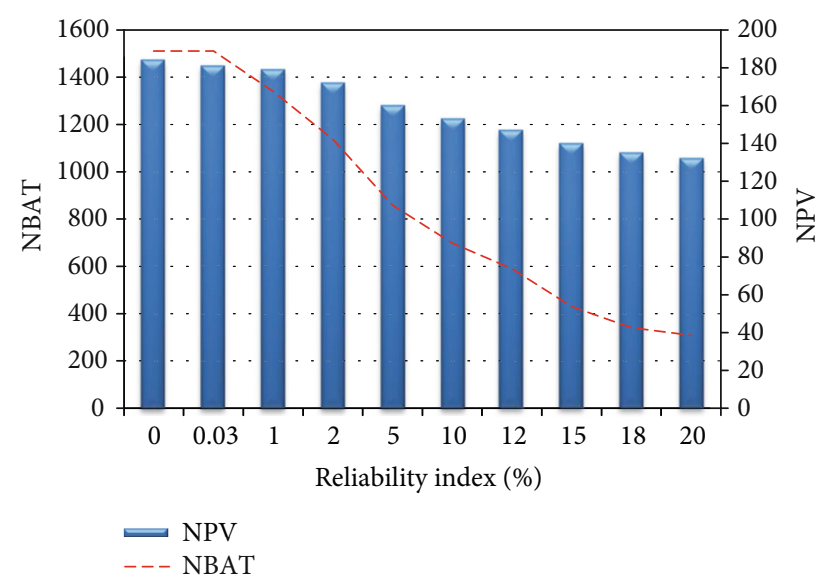

FIGURE 6: Number of optimal components vs. system reliability indexes.

where $P_{\mathrm{INV}}$ and $P_{\mathrm{BAT}}$ are the price of inverter/converter and battery, respectively.

According to the capital and replacement cost of the components (PV, battery, and inverter), the total annual capital and replacement cost is mathematically achieved as follows:

$$
\begin{aligned}
\mathrm{C} \& \mathrm{R}= & \mathrm{CRF} \times\left[N_{\mathrm{PV}} \times \mathrm{C} \& \mathrm{R}_{\mathrm{PV}}+N_{\mathrm{BAT}} \times \mathrm{C} \& \mathrm{R}_{\mathrm{BAT}}\right. \\
& \left.+N_{\mathrm{INV}} \times \mathrm{C} \& \mathrm{R}_{\mathrm{INV}}\right] .
\end{aligned}
$$

Here, $N_{\text {INV }}$ and $N_{\text {BAT }}$ represent the numbers of inverter and battery, respectively.

The annual O\&M cost of the components (PV, battery, and inverter) is mathematically achieved as follows:

$\mathrm{O} \& \mathrm{M}=N_{\mathrm{PV}} \cdot \mathrm{O} \& \mathrm{M}_{\mathrm{PV}}+N_{\mathrm{BAT}} \cdot \mathrm{O} \& \mathrm{M}_{\mathrm{BAT}}+N_{\mathrm{INV}} \cdot \mathrm{O} \& \mathrm{M}_{\mathrm{INV}} \cdot$

3.2. Constraints. To have a highly reliable system, the concept of the loss of load probability (LLP) must be consid-

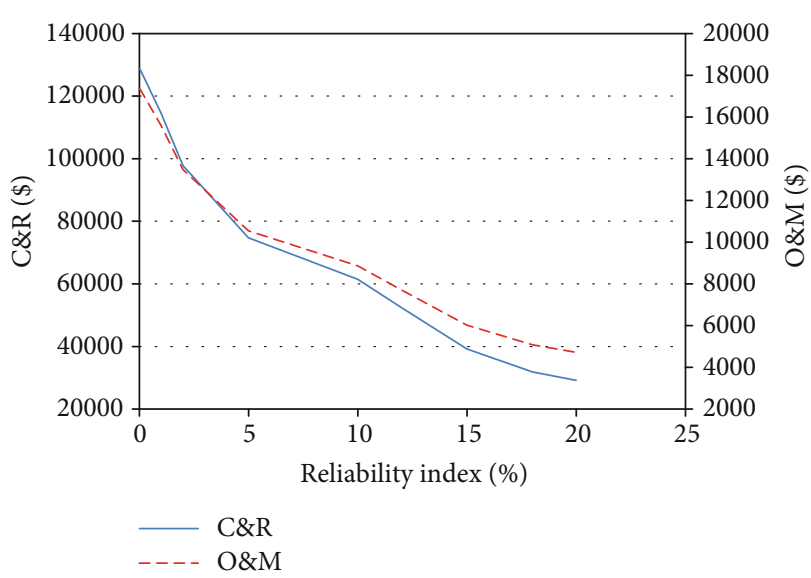

FIgURE 7: Operation and maintenance cost and capital and replacement cost vs. reliability indexes in the optimal condition.

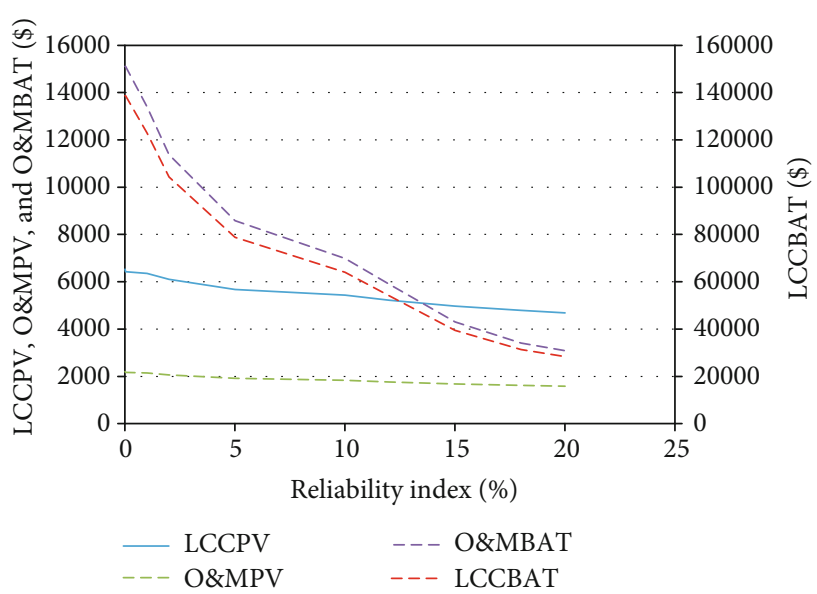

Figure 8: Cost index of optimal components vs. reliability indexes in the optimal condition.

ered in the optimization, which is mathematically modeled as follows:

$$
\operatorname{LLP}=\frac{\sum_{t=1}^{T} \operatorname{LLS}(t)}{\sum_{t=1}^{T} E_{\mathrm{Load}}(t)} .
$$

Here, LLS denotes to loss of load supply which is achieved based on generated energy $\left(E_{\mathrm{Gen}}\right)$ as follows:

$$
\operatorname{LLS}(t)=E_{L}(t)-E_{\mathrm{Gen}}(t)
$$

and LLP $\leq$ RIwhere RI stands the highest allowable value of LLP.

The numbers of PV panel and battery constraints and storage units are as follows:

$$
\begin{gathered}
0 \leq N_{\mathrm{PV}} \leq N_{\mathrm{PV}-\mathrm{Max}}, \\
0 \leq N_{\mathrm{BAT}} \leq N_{\mathrm{BAT}-\mathrm{Max}}, \\
S_{\mathrm{BAT}-\mathrm{Min}} \leq S_{\mathrm{BAT}, t} \leq S_{\mathrm{BAT}-\mathrm{Max}} .
\end{gathered}
$$




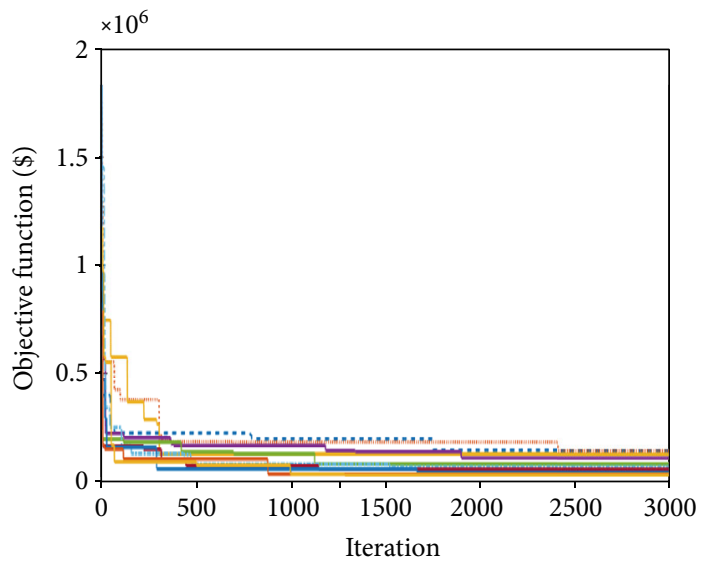

(a)

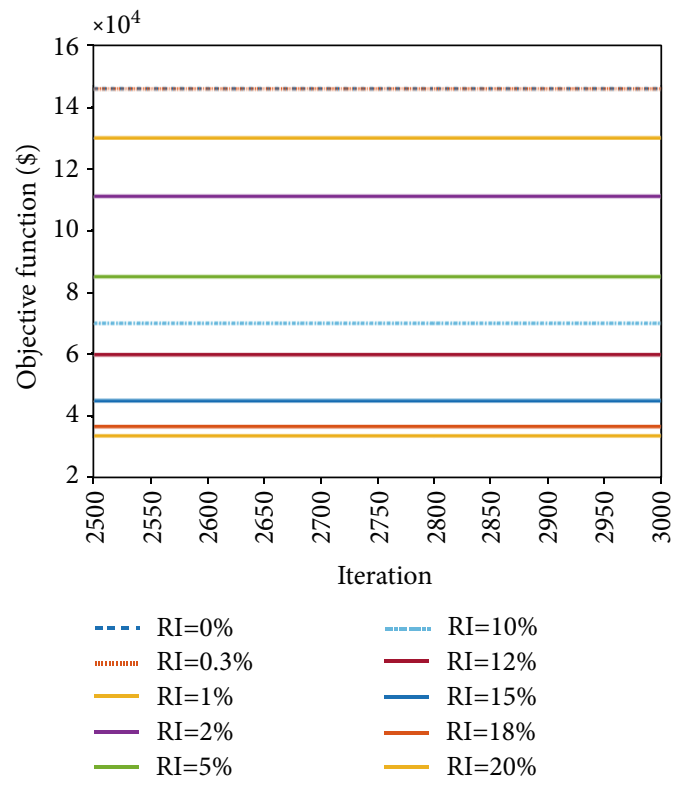

(b)

FIGURE 9: (a) The convergence characteristic of different reliability indexes on optimal hybrid solar/battery system; (b) zoom part.

Here, $N_{\mathrm{PV}-\mathrm{Max}}$ and $N_{\mathrm{BAT}-\mathrm{Max}}$ are the maximum numbers of PV panel and battery, respectively, $S_{\text {BAT-Max }}$ is the highest quantity of the state of charge, while its minimum amount $\left(S_{\text {BAT-Min }}\right)$ is achieved based on the depth of discharge (DOD) and its nominal capacity $\left(\mathrm{NC}_{\mathrm{BAT}}\right)$ as follows [44-46, 48-50]:

$$
S_{\mathrm{BAT}-\mathrm{Min}}=(1-\mathrm{DOD}) \cdot \mathrm{NC}_{\mathrm{BAT}} \cdot
$$

\section{Results and Discussion}

The presented optimization model is considered to achieve a case study in Rafsanjan. Rafsanjan is a city in the north-west of Kerman province, Iran, with an altitude of $1,460 \mathrm{~m}$ which is placed at $30^{\circ} 24^{\prime} 24^{\prime \prime} \mathrm{N} 55^{\circ} 59^{\prime} 38^{\prime \prime} \mathrm{E}$. The winters in Rafsanjan are cold and freezing as well as hot and dried in the summers. The ambient temperature usually differs from $-17^{\circ} \mathrm{C}$ to $43^{\circ} \mathrm{C}$. The case study includes around five homes located in a remote area of Rafsanjan, Iran. Actual data of solar insolation, ambient temperature, and typical load demand of the case study based on hourly distribution during a year are used in this study $(8760 \mathrm{~h})$. The residential load profile of the case study for five households is shown in Figure 2, in which the minimum and the maximum load demands of the system are 1.6 and $7.5 \mathrm{~kW}$. The ambient temperature and solar insolation profiles of the studied area are presented in Figure 3.

The specifications of hybrid system components are given in Table 1.

In this study, the MATLAB software is used to implement the modified harmony search (HS) algorithm. The harmony search algorithm was first introduced in 2001 [54]. HS is a type of emerging metaheuristic optimization algorithm based on three operators, namely, pitch adjusting rule, harmony memory considering rule, and random search. The HS is trying to mimic the process of the musicians' improvisation. Because of exploitation and ease of application, the HS has drawn worldwide attention mainly. The employed HS in the present study is denoted in the previous studies [55]. In a modified harmony search algorithm, the parameters of pitch adjusting rate and bandwidth of generation are improved for adjusting the convergence rate of the method to the optimal solution, while them constant in the original algorithm. The modified harmony search algorithm used in this paper is the same as that proposed in [41]. The parameters of the modified proposed optimization method used in this paper as harmony memory considering rate and the maximum number of iterations are considered 0.9 and 3000, respectively. Also, the maximum and minimum of pitch adjusting rate are 1 and 0.1, respectively. The maximum and minimum of generation bandwidth are 1 and 0.01 , respectively, which are determined by the atrial-and-error method. To provide valid results of the suggested algorithm, 30 independent runs are executed, and the optimal results are determined. In this optimal configuration of the hybrid solar/battery energy system, the control variables are numbers of PV panels (260-watt monocrystalline solar panel) and battery storage units (VMAX SLR155 12 V 155 Ah AGM deep cycle solar battery) that the minimum bound of these variables are set to 0 and also the maximum the bound of them are set to 200 and 20000, respectively. Figure 4 shows the flowchart of the suggested process. The optimal result of the suggested algorithm, in $\mathrm{RI}=2 \%$, shows that the optimal number of PV panels and battery storage is 172 and 1137, respectively. The best choice of TLCC and LLP is $\$ 111,280$ and $1.8516 \%$, respectively. Since changes in the reliability index affect the cost and the optimal number of components, it is necessary to examine the effects of the reliability index on the optimization of the system. 
TABLE 3: The results of the variations of the PV panel unit cost on the optimal variables and cost criteria (in \$) of the system.

\begin{tabular}{lccccccccccc}
\hline PV cost $\left(\$ / \mathrm{m}^{2}\right)$ & RI $(\%)$ & LLP $(\%)$ & $N_{\mathrm{PV}}$ & $N_{\text {BAT }}$ & LCC $_{\mathrm{PV}}$ & LCC $_{\mathrm{BAT}}$ & C\&R & O\&M & O\&M & O\&M $_{\text {BAT }}$ & TLCC \\
\hline 50 & 2 & 1.9927 & 171 & 1114 & 3,699 & 102,240 & 93,520 & 13,237 & 2052 & 11,140 & 106,760 \\
100 & 2 & 1.7620 & 173 & 1125 & 5,409 & 103,250 & 96,105 & 13,371 & 2076 & 11,250 & 109,480 \\
125 & 2 & 1.8339 & 172 & 1151 & 6,206 & 105,636 & 99,040 & 13,619 & 2064 & 11,510 & 112,660 \\
150 & 2 & 1.8377 & 172 & 1148 & 7,034 & 105,360 & 99,623 & 13,589 & 2064 & 11,480 & 113,220 \\
200 & 2 & 1.9658 & 171 & 1132 & 8,640 & 103,892 & 99,933 & 13,417 & 2052 & 11,320 & 113,350 \\
250 & 2 & 1.9608 & 171 & 1136 & 10,287 & 104,259 & 101,907 & 13,457 & 2052 & 11,360 & 115,640 \\
300 & 2 & 1.9709 & 171 & 1128 & 11,934 & 103,525 & 102,900 & 13,377 & 2052 & 11,280 & 116,280 \\
350 & 2 & 1.9633 & 171 & 1134 & 13,358 & 104,075 & 105,037 & 13,437 & 2052 & 11,340 & 118,480 \\
400 & 2 & 1.8137 & 172 & 1167 & 15,317 & 107,104 & 109,460 & 13,779 & 2064 & 11,670 & 123,240 \\
450 & 2 & 1.5936 & 174 & 1161 & 17,171 & 106,553 & 110,799 & 13,743 & 2088 & 11,610 & 124,550 \\
500 & 2 & 1.7103 & 173 & 1166 & 18,739 & 107,012 & 112,788 & 13,781 & 2076 & 11,660 & 126,570 \\
\hline
\end{tabular}

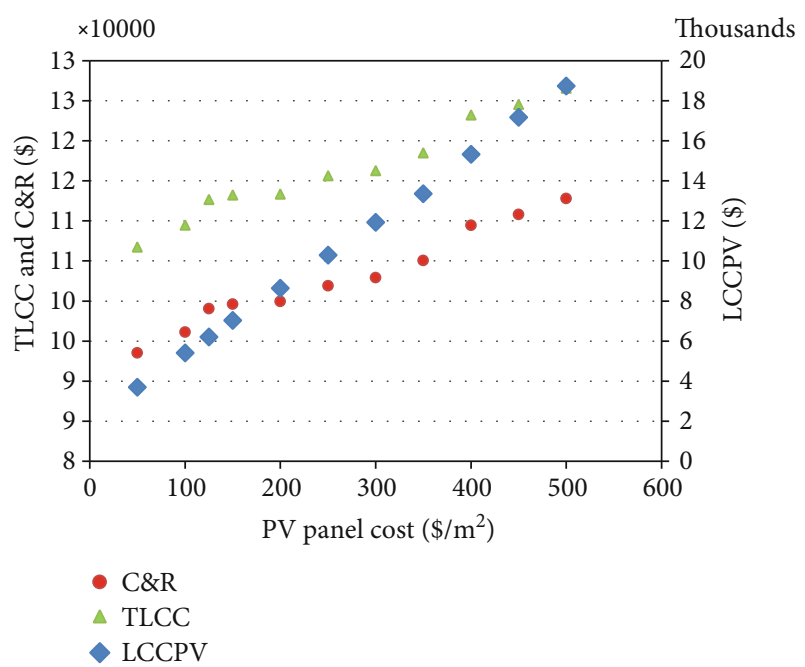

Figure 10: TLCC, LCC $_{\mathrm{PV}}$, and C\&R of the hybrid system vs. PV panel unit cost in the optimal condition.

4.1. Effects of the Reliability Index. The optimal configurations of hybrid solar/battery energy system for different reliability indexes ( 0 to $20 \%$ ) are shown in Table 2 . In RI $=0 \%$, the optimal number of PV panels, battery storage, and TLCC is 184,1511 , and $\$ 146,070$, respectively. It is found that by reducing the reliability index from 2 to $0 \%$, the values of numbers of PV panels, battery storage, and TLCC increase to 12,374 , and $\$ 34,790$, respectively. It can be seen that the LCC of the batteries and panels are $\$ 138,675$ and $\$ 6530$ for in this case, and also, the annual operation and maintenance cost and annual capital and replacement cost of the optimal hybrid system are $\$ 17,363$ and $\$ 128,661$, respectively. The O\&M costs of the batteries and panels are $\$ 15,110$ and $\$ 2,208$, respectively.

In RI $=5 \%$, the optimal values of $N_{\mathrm{PV}}, N_{\mathrm{BAT}}$, TLCC, and LLP are $160,858, \$ 85,250$, and $4.5051 \%$, respectively. It is found that by increasing RI from 2 to $5 \%$, the values of $N_{\mathrm{PV}}, N_{\mathrm{BAT}}$, and TLCC decrease to $7 \%, 25 \%$, and $23 \%$, respectively, and also show that the values of $\mathrm{LCC}_{\mathrm{PV}}, \mathrm{LC}$ $\mathrm{C}_{\mathrm{BAT}}, \mathrm{C} \& \mathrm{R}$, and O\&M of optimal system decrease to $\$ 425$, $\$ 25,606, \$ 23,098$, and $\$ 2,934$, respectively. In this case, the optimal values of O\&M of the batteries and panels are $\$ 8,580$ and $\$ 1,920$, respectively. For RI equal to $10 \%$ and $12 \%$, the optimal value of TLCC is decreased to $\$ 70,310$ and $\$ 60,190$, respectively, and the optimal numbers of PV and batteries are 153 and 147 and 698 and 590, respectively. In $\mathrm{RI}=15 \%$, the minimal TLCC is $\$ 45,260$, and the optimal values of $N_{\mathrm{PV}}, N_{\mathrm{BAT}}$, and LLP are 140,430 , and $14.6732 \%$, respectively. For RI equal to $18 \%$ and $20 \%$, the optimal values of TLCC are decrease to $\$ 36,910$ and $\$ 33,860$, respectively, and the optimal C\&R and O\&M of system are 31,830 and $29,143 \$$ and 5,075 and $4,719 \$$, respectively. It can be seen that by increasing the reliability index, the optimal components of the hybrid system and TLCC are decreased, as shown in Figures 5 and 6. Variation in operation and maintenance cost and capital and replacement cost of the hybrid schemes in optimized situations versus reliability index is presented in Figure 7. In Figure 8, variation in cost criteria of the optimal system component (LCC of the batteries and panels and O\&M of the batteries and panels) versus $\mathrm{RI}$ is presented. It is found that the cost criteria reduce by increment in the value of the RI. The convergence characteristic of different reliability indexes on optimal hybrid solar/battery scheme is presented in Figure 9, which shows that by reducing reliability index from 20 to $0 \%$, the objective function value is increase from $\$ 33,860$ to $\$ 146,070$, respectively.

4.2. Sensitivity Analysis of the Economic Parameters. The results of the variations of the PV panel unit cost on the optimal variables and cost criteria (in \$) of the hybrid solar/battery scheme for $\mathrm{RI}=2 \%$ are given in Table 3 . It is observed that the value of LLP and TLCC of the hybrid system, for PV cost equal to $250 \$ / \mathrm{m}^{2}$, is $1.9608 \%$ and $\$ 115,640$, respectively. In this case, the optimal values of $N_{\mathrm{PV}}$ and $N_{\mathrm{BAT}}$ are 171 and 1136; also, the LCC of the panels and batteries are \$10,287 and $\$ 104,259$, respectively, and the optimal C\&R and O\&M of the system are $\$ 101,907$ and $\$ 13,457$, respectively.

In $\mathrm{PV}$ cost $=50 \$ / \mathrm{m}^{2}$, the optimal number of PV panels, battery storage, and TLCC is 171,1114 , and $\$ 106,760$, respectively. It is found that by reducing PV cost from 250 to $50 \$ / \mathrm{m}^{2}$, the values of TLCC, C\&R, and $\mathrm{LCC}_{\mathrm{PV}}$ decrease to $\$ 8,880, \$ 8,387$, and $\$ 6,588$, respectively. It can be seen that the TLCC, C\&R, and $\mathrm{LCC}_{\mathrm{PV}}$ are $\$ 106,760, \$ 93,520$, 
TABLE 4: The results of the variations of the battery unit cost on the optimal variables and cost criteria (in \$) of the system.

\begin{tabular}{lccccccccccc}
\hline Battery cost (\$) & RI (\%) & LLP (\%) & $N_{\text {PV }}$ & $N_{\text {BAT }}$ & LCC $_{\text {PV }}(\$)$ & LCC $_{\text {BAT }}$ & C\&R & O\&M & O\&M $_{\text {PV }}$ & O\&M $_{\text {BAT }}$ & TLCC \\
\hline 50 & 2 & 1.6722 & 173 & 1193 & 6,140 & 27,666 & 20,573 & 14,051 & 2,076 & 11,930 & 34640 \\
100 & 2 & 1.9634 & 171 & 1134 & 6,070 & 41,255 & 34,705 & 13,437 & 2,052 & 11,340 & 48140 \\
150 & 2 & 1.9482 & 171 & 1146 & 6,070 & 56,807 & 50,137 & 13,557 & 2,052 & 11,460 & 63690 \\
200 & 2 & 1.9159 & 171 & 1169 & 6,070 & 73,366 & 66,466 & 13,787 & 2,052 & 11,690 & 80250 \\
250 & 2 & 1.8011 & 172 & 1177 & 6,105 & 89,392 & 82,436 & 13,879 & 2,064 & 11,770 & 96330 \\
300 & 2 & 1.9927 & 171 & 1114 & 6,070 & 99,301 & 92,951 & 13,237 & 2,052 & 11,140 & 106190 \\
350 & 2 & 1.7292 & 173 & 1151 & 6,140 & 117,781 & 111,108 & 13,631 & 2,076 & 11,510 & 124740 \\
400 & 2 & 1.9709 & 171 & 1128 & 6,070 & 130,305 & 123,820 & 13,377 & 2,052 & 11,280 & 137190 \\
450 & 2 & 1.8377 & 172 & 1148 & 6,105 & 147,758 & 141,091 & 13,589 & 2,064 & 11,480 & 154680 \\
500 & 2 & 1.9071 & 171 & 1176 & 6,070 & 166,873 & 159,903 & 13,857 & 2,052 & 11,760 & 173760 \\
550 & 2 & 1.9481 & 171 & 1146 & 6,070 & 177,732 & 171,062 & 13,557 & 2,052 & 11,460 & 184620 \\
\hline
\end{tabular}

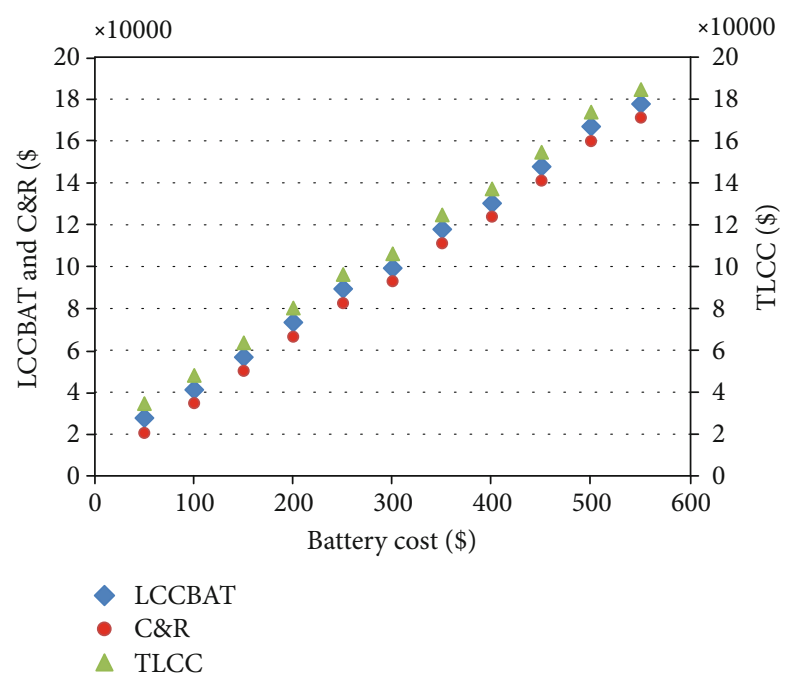

Figure 11: TLCC, LCC $_{\text {BAT }}$, and C\&R of the hybrid system vs. battery cost in the optimal condition.

and $\$ 3,699$, for in this case, and also, the annual O\&M costs of the optimal hybrid system and PV panels are $\$ 13,237$ and $\$ 2052$, respectively. In PV cost $=500 \$ / \mathrm{m}^{2}$, the optimal values of TLCC and LLP are $\$ 126,570$ and $1.7103 \%$. It is found that by increasing PV cost from 200 to $500 \$ / \mathrm{m}^{2}$, the values of TLCC and C\&R increase to $9.5 \%$ and $10.7 \%$, respectively. It can be seen that by increasing the PV panel unit cost, the TLCC and C\&R of the hybrid system, and the LCC of PV panels are increased, as shown in Figure 10.

The results of the variations of the battery unit cost on the optimal variables and cost criteria (in \$) of the hybrid solar/battery scheme for $\mathrm{RI}=2 \%$ are given in Table 4 . It is shown that the value of LLP and TLCC of the hybrid system, for battery cost equal to $\$ 300$, is $1.9927 \%$ and $\$ 106190$, respectively. In this case, the optimal values of numbers of panels and batteries are 171 and 1114; also, the LCC of the panels and batteries are $\$ 6,070$ and $\$ 99,301$, respectively, and the optimal C\&R and O\&M of the system are $\$ 92,951$ and $\$ 13,237$, respectively.

In battery cost $=\$ 50$, the optimal number of PV panels, battery storage, and TLCC is 173,1193 , and $\$ 34640$, respec- tively. It can be seen that by reducing battery cost from 300 to $\$ 50$, the values of TLCC, C\&R, and $\mathrm{LCC}_{\mathrm{BAT}}$ decrease to $\$ 71,550, \$ 72,378$, and $\$ 71,635$, respectively. It can be seen that the TLCC, C\&R, and $\mathrm{LCC}_{\mathrm{BAT}}$ are $\$ 34640, \$ 20,573$, and $\$ 27,666$, for in this case, and also, the annual O\&M costs of the optimal hybrid system and batteries are $\$ 14,051$ and $\$ 11,930$, respectively. In battery cost $=\$ 550$, the optimal values of TLCC and LLP are $\$ 184,620$ and $1.9481 \%$, respectively. It is found that by increasing battery cost from 300 to $\$ 550$, the values of TLCC and C\&R increase to $74 \%$ and $84 \%$, respectively. In Figure 11, variation in TLCC, LCC $_{\text {BAT }}$ , and C\&R of the optimal hybrid system versus battery cost is presented. It can be seen that by increasing the battery unit cost, the TLCC and C\&R of the hybrid system and the LCC of batteries are increased.

\section{Conclusion}

In this paper, an optimal configuration of a stand-alone hybrid photovoltaic (PV)/battery energy storage system is investigated to provide the load demand in Iran. The objective function is a minimization of total life cycle cost (TLCC) subject to the reliability index (loss of load probability) by a modified harmony search algorithm. Also, sensitivity analysis and effects of reliability index (0 to 20\%) and economic parameters based on photovoltaic and battery prices are presented, and the results are analyzed. The results show that, by reducing reliability index from 2 to $0 \%$, the values of number of PV panels, battery storage, and TLCC increase to $7 \%, 33 \%$, and $31 \%$, respectively, and by increasing the reliability index from 2 to $5 \%$, the values of numbers of PV panels, batteries, and TLCC decrease to $7 \%, 25 \%$, and $23 \%$, respectively, and also show that by increasing PV cost from 200 to $500 \$ / \mathrm{m}^{2}$, the values of TLCC and C\&R increase to $9.5 \%$ and $10.7 \%$, respectively, and by reducing PV cost from 250 to $50 \$ / \mathrm{m}^{2}$, the values of TLCC and C\&R decrease to $7.7 \%$ and $8.2 \%$, respectively. It is found that by increasing battery cost from 300 to $\$ 550$, the values of TLCC and $\mathrm{C} \& \mathrm{R}$ increase to $74 \%$ and $84 \%$, respectively, and by reducing battery cost from 300 to $\$ 50$, the values of TLCC and C\&R decrease to $67 \%$ and $78 \%$, respectively. Future work will be investigated different stand-alone hybrid energy systems 
based on backup system, which process hybrid energy system types and the sensitivity analysis.

\section{Nomenclature}

CRF: Capital recover factor

C\&R: Capital and replacement

C\&R $\mathrm{R}_{\mathrm{BAT}}$ : Present worth of battery

$\mathrm{C} \& \mathrm{R}_{\mathrm{PV}}$ : Capital and replacement cost of PV panel

$\mathrm{C} \& \mathrm{R}_{\mathrm{INV}}$ : Present worth of inverter/converter

DOD: Depth of discharge

$E_{\mathrm{Gen}}$ : $\quad$ Generated energy

$E_{L}: \quad$ Energy demand

HS: $\quad$ Harmony search

LLP: $\quad$ Loss of load probability

LLS: $\quad$ Loss of load supply

$\mathrm{LCC}_{\mathrm{PV}}$ : Life cycle cost of PV panels

LCC $_{\mathrm{BAT}}$ : Life cycle cost of batteries

$N_{T}: \quad$ Temperature coefficient $\left(1 /{ }^{\circ} \mathrm{C}\right)$

$N_{\text {PV }}$ : Number of PV panels

$N_{\text {INV }}$ : Number of inverter

$N_{\text {BAT }}: \quad$ Number of battery

$N_{\text {PV-Max }}$ : Maximum number of PV panel

$N_{\text {BAT-Max }}$ : Maximum number of battery

$\mathrm{NC}_{\mathrm{BAT}}$ : Nominal capacity of battery

NOCT: $\quad$ Normal operating cell temperature $\left({ }^{\circ} \mathrm{C}\right)$

n: $\quad$ System life span

O\&M: Operation and maintenance

O\&M $\mathrm{MV}_{\mathrm{PV}}$ : O\&M cost of the PV panel

O\&M $\mathrm{MAT}_{\mathrm{BAT}}$ O\&M cost of the battery

O\&M $\mathrm{M}_{\mathrm{INV}}: \mathrm{O} \& \mathrm{M}$ cost of the inverter

PV: $\quad$ Photovoltaic

$p_{\mathrm{PV}}$ : $\quad$ Generating power of PV panel $(\mathrm{kW})$

$P_{R, \mathrm{PV}}$ : $\quad$ Rated power of the PV panel

$P_{\mathrm{PV}}$ : $\quad$ Total produced power by $\mathrm{PV}$ panels $(\mathrm{kW})$

$P_{D}: \quad$ Hourly demand

$P_{\mathrm{INV}}: \quad$ Output power of an inverter

$P_{\mathrm{INV}}: \quad$ Price of inverter/converter

$P_{\mathrm{BAT}}: \quad$ Price of battery

$r: \quad$ Interest rate

$\boldsymbol{R}: \quad$ Solar radiation $\left(\mathrm{W} / \mathrm{m}^{2}\right)$

RI: Reliability index/or highest allowable value of LLP

$R_{\text {ref: }}: \quad$ Reference solar radiation $\left(\mathrm{W} / \mathrm{m}^{2}\right)$

$S_{\text {BAT }}(t): \quad$ State of charge of battery at time $\boldsymbol{t}$

$S_{\text {BAT-Max }}$ : Highest quantity of the state of charge

$S_{\text {BAT-Min }}$ : Minimum amount of the state of charge

TLCC: Total life cycle cost

$T_{\text {air }}: \quad$ Ambient temperature $\left({ }^{\circ} \mathrm{C}\right)$

$T_{\text {ref: }}$ : $\quad$ Reference temperature $\left({ }^{\circ} \mathrm{C}\right)$

$T_{c}: \quad$ Temperature of the cell

$\omega: \quad$ Rate of hourly self-discharge

$\eta_{\mathrm{INV}}: \quad$ Efficiency of the inverter (\%)

$\eta_{\mathrm{BC}}: \quad$ Battery charging efficiency $(\%)$

$\eta_{\mathrm{BDC}}: \quad$ Battery discharging efficiency (\%).

\section{Data Availability}

No data were used to support this study.

\section{Conflicts of Interest}

The authors declare that they have no conflicts of interest.

\section{References}

[1] A. Ghasemi and M. Enayatzare, "Optimal energy management of a renewable-based isolated microgrid with pumped- storage unit and demand response," Renewable Energy, vol. 123, pp. 460-474, 2018.

[2] M. S. Javed, A. Song, and T. Ma, "Techno-economic assessment of a stand-alone hybrid solar-wind-battery system for a remote island using genetic algorithm," Energy, vol. 176, pp. 704-717, 2019.

[3] W. Cai, X. Li, A. Maleki et al., "Optimal sizing and location based on economic parameters for an off-grid application of a hybrid system with photovoltaic, battery and diesel technology," Energy, vol. 201, article 117480, 2020.

[4] Y. Zhang, G. Liu, C. Zhang et al., "Low-cost $\mathrm{MgFe}_{\mathrm{x}} \mathrm{Mn}_{2-\mathrm{x}} \mathrm{O}_{4}$ cathode materials for high-performance aqueous rechargeable magnesium-ion batteries," Chemical Engineering Journal, vol. 392, p. 123652, 2020.

[5] H. Yin, C. Han, Q. Liu, F. Wu, F. Zhang, and Y. Tang, "Recent advances and perspectives on the polymer electrolytes for sodium/potassium-ion batteries," Small, vol. 17, no. 31, article 2006627, 2021.

[6] X. Zhao, B. Gu, F. Gao, and S. Chen, "Matching model of energy supply and demand of the integrated energy system in coastal areas," Journal of Coastal Research, vol. 103, no. sp1, pp. 983-989, 2020.

[7] L. Zhang, H. Zheng, T. Wan, D. Shi, L. Lyu, and G. Cai, “An integrated control algorithm of power distribution for islanded microgrid based on improved virtual synchronous generator," IET Renewable Power Generation, vol. 15, no. 12, pp. 26742685, 2021.

[8] M. Das, M. A. K. Singh, and A. Biswas, "Techno-economic optimization of an off-grid hybrid renewable energy system using metaheuristic optimization approaches - Case of a radio transmitter station in India," Energy Conversion and Management, vol. 185, pp. 339-352, 2019.

[9] E. Saedpanah, R. F. Asrami, A. Sohani, and H. Sayyaadi, "Life cycle comparison of potential scenarios to achieve the foremost performance for an off-grid photovoltaic electrification system," Journal of Cleaner Production, vol. 242, article 118440, 2020.

[10] R. Fardi Asrami, A. Sohani, E. Saedpanah, and H. Sayyaadi, "Towards achieving the best solution to utilize photovoltaic solar panels for residential buildings in urban areas," Sustainable Cities and Society, vol. 71, article 102968, 2021.

[11] P. Nagapurkar and J. D. Smith, "Techno-economic optimization and environmental Life Cycle Assessment (LCA) of microgrids located in the US using genetic algorithm," Energy Conversion and Management, vol. 181, pp. 272-291, 2019.

[12] G. Yu, Z. Meng, H. Ma, and L. Liu, “An adaptive marine predators algorithm for optimizing a hybrid PV/DG/battery system for a remote area in China," Energy Reports, vol. 7, pp. 398412, 2021.

[13] M. A. Ashraf, Z. Liu, A. A. Alizadeh, S. Nojavan, K. Jermsittiparsert, and D. Zhang, "Designing an optimized configuration for a hybrid PV/diesel/battery energy system based on metaheuristics: a case study on Gobi Desert," Journal of Cleaner Production, vol. 270, article 122467, 2020. 
[14] D. Cho and J. Valenzuela, "Optimization of residential off-grid PV-battery systems," Solar Energy, vol. 208, pp. 766-777, 2020.

[15] B. Mukhopadhyay and D. Das, "Multi-objective dynamic and static reconfiguration with optimized allocation of PV-DG and battery energy storage system," Renewable and Sustainable Energy Reviews, vol. 124, article 109777, 2020.

[16] Y. Jiang, L. Kang, and Y. Liu, "Multi-objective design optimization of a multi-type battery energy storage in photovoltaic systems," Journal of Energy Storage, vol. 39, article 102604, 2021.

[17] K. Anoune, M. Ghazi, M. Bouya et al., "Optimization and techno-economic analysis of photovoltaic-wind-battery based hybrid system," Journal of Energy Storage, vol. 32, article 101878, 2020.

[18] T. A. Ajiwiguna, G.-R. Lee, B.-J. Lim, S.-H. Cho, and C.D. Park, "Optimization of battery-less PV-RO system with seasonal water storage tank," Desalination, vol. 503, article 114934, 2021.

[19] D. Zhu, B. Wang, H. Ma, and H. Wang, "Evaluating the vulnerability of integrated electricity-heat-gas systems based on the high-dimensional random matrix theory," CSEE Journal of Power and Energy Systems, vol. 6, no. 4, pp. 878-889, 2019.

[20] B. Li, G. Xiao, R. Lu, R. Deng, and H. Bao, “On feasibility and limitations of detecting false data injection attacks on power grid state estimation using D-FACTS devices," IEEE Transactions on Industrial Informatics, vol. 16, no. 2, pp. 854-864, 2020.

[21] X. Chen, T. Wang, R. Ying, and Z. Cao, "A fault diagnosis method considering meteorological factors for transmission networks based on P systems," Entropy, vol. 23, no. 8, article 1008, 2021.

[22] T. Wang, W. Liu, J. Zhao, X. Guo, and V. Terzija, "A rough setbased bio-inspired fault diagnosis method for electrical substations," International Journal of Electrical Power \& Energy Systems, vol. 119, article 105961, 2020.

[23] T. Wang, X. Wei, J. Wang et al., "A weighted corrective fuzzy reasoning spiking neural $P$ system for fault diagnosis in power systems with variable topologies," Engineering Applications of Artificial Intelligence, vol. 92, article 103680, 2020.

[24] Z. Huang, T. Wang, W. Liu, L. Valencia-Cabrera, M. J. PérezJiménez, and P. Li, "A fault analysis method for three-phase induction motors based on spiking neural P systems," Complexity, vol. 2021, Article ID 2087027, 19 pages, 2021.

[25] C. Zhang and H. Wang, "Swing vibration control of suspended structure using active rotary inertia driver system: parametric analysis and experimental verification," Applied Sciences, vol. 9, no. 15, article 3144, 2019.

[26] C. Mokhtara, B. Negrou, N. Settou, A. Bouferrouk, and Y. Yao, "Design optimization of grid-connected PV-hydrogen for energy prosumers considering sector-coupling paradigm: case study of a university building in Algeria," International Journal of Hydrogen Energy, vol. 46, no. 75, pp. 37564-37564, 2020.

[27] H. El-houari, A. Allouhi, T. Salameh, T. Kousksou, A. Jamil, and B. El Amrani, "Energy, economic, environment (3E) analysis of WT-PV-battery autonomous hybrid power plants in climatically varying regions," Sustainable Energy Technologies and Assessments, vol. 43, article 100961, 2021.

[28] T. Salameh, M. A. Abdelkareem, A. Olabi, E. T. Sayed, M. alChaderchi, and H. Rezk, "Integrated standalone hybrid solar $\mathrm{PV}$, fuel cell and diesel generator power system for battery or supercapacitor storage systems in Khorfakkan, United Arab
Emirates," International Journal of Hydrogen Energy, vol. 46, no. 8, pp. 6014-6027, 2021.

[29] O. Krishan and S. Suhag, "Grid-independent PV system hybridization with fuel cell- battery/supercapacitor: Optimum sizing and comparative techno-economic analysis," Sustainable Energy Technologies and Assessments, vol. 37, article 100625, 2020.

[30] J. Wesly, A. C. Brasil Jr., C. A. Frate, and R. K. Badibanga, "Techno-economic analysis of a PV-wind-battery for a remote community in Haiti," Case Studies in Chemical and Environmental Engineering, vol. 2, article 100044, 2020.

[31] D. Magnor and D. U. Sauer, "Optimization of PV battery systems using genetic algorithms," Energy Procedia, vol. 99, pp. 332-340, 2016.

[32] W. Zhang, A. Maleki, A. K. Birjandi, M. Alhuyi Nazari, and O. Mohammadi, "Discrete Optimization Algorithm for Optimal Design of a Solar/Wind/Battery Hybrid Energy Conversion Scheme," International Journal of Low-Carbon Technologies, vol. 16, no. 2, pp. 326-340, 2021.

[33] M. Tahani, N. Babayan, and A. Pouyaei, "Optimization of $\mathrm{PV} /$ wind/battery stand-alone system, using hybrid FPA/SA algorithm and CFD simulation, case study: Tehran," Energy Conversion and Management, vol. 106, pp. 644-659, 2015.

[34] A. Almadhor, H. T. Rauf, M. A. Khan, S. Kadry, and Y. Nam, "A Hybrid Algorithm (BAPSO) for Capacity Configuration Optimization in a Distributed Solar PV Based Microgrid," Energy Reports, 2021.

[35] A. Yahiaoui, F. Fodhil, K. Benmansour, M. Tadjine, and N. Cheggaga, "Grey wolf optimizer for optimal design of hybrid renewable energy system PV- Diesel Generator-Battery: Application to the case of Djanet city of Algeria," Solar Energy, vol. 158, pp. 941-951, 2017.

[36] N. Alshammari and J. Asumadu, "Optimum unit sizing of hybrid renewable energy system utilizing harmony search, Jaya and particle swarm optimization algorithms," Sustainable Cities and Society, vol. 60, article 102255, 2020.

[37] N. Alshammari and J. Asumadu, Optimum unit sizing of hybrid renewable energy system utilizing Harmony Search, Jaya and particle swarm optimization algorithms, no. article 102255, 2020Sustainable Cities and Society, 2020.

[38] A. Chauhan and R. Saini, "Discrete harmony search based size optimization of integrated renewable energy system for remote rural areas of Uttarakhand state in India," Renewable Energy, vol. 94, pp. 587-604, 2016.

[39] W. Zhang, A. Maleki, F. Pourfayaz, and M. S. Shadloo, “An artificial intelligence approach to optimization of an off-grid hybrid wind/hydrogen system," International Journal of Hydrogen Energy, vol. 46, no. 24, pp. 12725-12738, 2021.

[40] X. Yu, W. Li, A. Maleki, M. A. Rosen, A. K. Birjandi, and L. Tang, "Selection of optimal location and design of a standalone photovoltaic scheme using a modified hybrid methodology," Sustainable Energy Technologies and Assessments, vol. 45, article 101071, 2021.

[41] A. Maleki, M. A. Nazari, and F. Pourfayaz, "Harmony Search Optimization for Optimum Sizing of Hybrid Solar Schemes Based on Battery Storage Unit," Energy Reports, vol. 6, pp. 102-111, 2020.

[42] M. S. Ismail, M. Moghavvemi, and T. Mahlia, “Techno-economic analysis of an optimized photovoltaic and diesel generator hybrid power system for remote houses in a tropical 
climate," Energy Conversion and Management, vol. 69, pp. 163-173, 2013.

[43] R. Belfkira, L. Zhang, and G. Barakat, "Optimal sizing study of hybrid wind/PV/diesel power generation unit," Solar Energy, vol. 85, no. 1, pp. 100-110, 2011.

[44] A. Ogunjuyigbe, T. Ayodele, and O. Akinola, "Optimal allocation and sizing of PV/wind/split-diesel/battery hybrid energy system for minimizing life cycle cost, carbon emission and dump energy of remote residential building," Applied Energy, vol. 171, pp. 153-171, 2016.

[45] A. L. Bukar, C. W. Tan, and K. Y. Lau, "Optimal sizing of an autonomous photovoltaic/wind/battery/diesel generator microgrid using grasshopper optimization algorithm," Solar Energy, vol. 188, pp. 685-696, 2019.

[46] B. A. Bhayo, H. H. Al-Kayiem, and S. I. Gilani, "Assessment of standalone solar PV-battery system for electricity generation and utilization of excess power for water pumping," Solar Energy, vol. 194, pp. 766-776, 2019.

[47] Z. W. Geem, "Size optimization for a hybrid photovoltaicwind energy system," International Journal of Electrical Power \& Energy Systems, vol. 42, no. 1, pp. 448-451, 2012.

[48] M. Alramlawi, E. Mohagheghi, and P. Li, "Predictive activereactive optimal power dispatch in PV-battery-diesel microgrid considering reactive power and battery lifetime costs," Solar Energy, vol. 193, pp. 529-544, 2019.

[49] M. I. Hlal, V. K. Ramachandaramurthy, A. Sarhan, A. Pouryekta, and U. Subramaniam, "Optimum battery depth of discharge for off-grid solar PV/battery system," Journal of Energy Storage, vol. 26, article 100999, 2019.

[50] G. Perkins, "Techno-economic comparison of the levelised cost of electricity generation from solar PV and battery storage with solar PV and combustion of bio-crude using fast pyrolysis of biomass," Energy Conversion and Management, vol. 171, pp. 1573-1588, 2018.

[51] A. Maleki, "Design and optimization of autonomous solarwind-reverse osmosis desalination systems coupling battery and hydrogen energy storage by an improved bee algorithm," Desalination, vol. 435, pp. 221-234, 2018.

[52] http://www.wholesalesolar.com/.

[53] W. Zhang, A. Maleki, and M. A. Rosen, "A heuristic-based approach for optimizing a small independent solar and wind hybrid power scheme incorporating load forecasting," Journal of Cleaner Production, vol. 241, article 117920, 2019.

[54] Z. W. Geem, J. H. Kim, and G. V. Loganathan, "A new heuristic optimization algorithm: harmony search," Simulation, vol. 76, no. 2, pp. 60-68, 2001.

[55] A. Maleki, A. Hajinezhad, and M. A. Rosen, "Modeling and optimal design of an off-grid hybrid system for electricity generation using various biodiesel fuels: a case study for Davarzan, Iran," Biofuels, vol. 7, no. 6, pp. 699-712, 2016. 